\title{
Microcirugía transoral con láser en cáncer laríngeo
}

\section{Transoral laser microsurgery in laryngeal cancer}

\author{
José F. Gallegos-Hernández*
}

Departamento de Tumores de Cabeza y Cuello, Hospital de Oncología, Centro Médico Nacional Siglo XXI, Instituto Mexicano del Seguro Social, Ciudad de México, México

Sr. Editor:

El interesante artículo de Tamez-Velarde, et al. ${ }^{1}$ titulado Microcirugía transoral con láser para el cáncer glótico temprano en un hospital de tercer nivel en Ciudad de México es el motivo de la presente con el objeto de comentar algunos conceptos en él vertidos.

En el cáncer glótico incipiente (Tis y cT1), la radioterapia y la resección transoral con láser son considerados actualmente de primera elección, con nivel de evidencia 1, con el mismo valor oncológico y una tasa similar de supervivencia a 5 años $^{2}$. La calidad de voz es diferente, siendo superior con radioterapia ${ }^{3}$. Desafortunadamente, los autores no la evalúan en su estudio, aunque es una variable importante de medir en etapas tempranas. Es menester mencionar que, en un metaanálisis ${ }^{4}$, la tasa de preservación orgánica es mayor con cirugía láser probablemente porque más pacientes con factores pronóstico adversos son tratados con radiación.

El tratamiento de cT2 depende de la extensión de la neoplasia, ya que puede incluir desde un tumor transglótico con movilidad cordo-aritenoidea normal hasta uno limitado a la cuerda vocal, pero con alteración de la movilidad, y ambos tienen pronóstico y tratamiento diferentes. Estas características no se precisan en el artículo; es interesante que la tasa de recaída es del $11 \%$, ligeramente mayor que en pacientes con Tis-cT1 $(9.6 \%)$.
Las diferencias en la localización tumoral en cT2 son fundamentales, porque los que tienen infiltración ventricular o de banda ventricular tienen mayor tasa de linfofilia, por lo que se debe realizar disección de cuello electiva y selectiva; no hacerlo aumenta el riesgo de recaída o progresión, lo cual pudo haber sucedido en el paciente sometido a laringectomía.

La tasa de recaída tras la resección con láser en este artículo es excelente, del 10\%, lo que implica un control local en el $90 \%$, similar a lo que la radioterapia externa ofrece. Llama la atención que, a pesar del seguimiento estrecho, un paciente con recurrencia requirió laringectomía total y quimio-radioterapia adyuvante, lo cual traduce una recaída locorregional avanzada. Los autores no precisan si este paciente fue clasificado previamente como cT2, tal vez explicado por una extensión supraglótica inicial del tumor o por una subetapificación. Nueve pacientes mueren sin neoplasia por otras causas, pero no se dice si habían cumplido con el tiempo mínimo para descartar una recaída (2 años). Queda la duda de si los porcentajes de recaída son mayores, al ser 31 los adecuadamente vigilados y no 40. Así mismo, una resección transoral en cT2 podría implicar (de acuerdo con la extensión) alteraciones en la deglución y consecuentemente aspiración; no mencionan si ocurrió en la serie ni se discute si pudo haber sido causa de complicaciones que causaran la muerte en los nueve pacientes mencionados.

\section{Correspondencia:}

*José F. Gallegos-Hernández

Avda. Cuauhtémoc 330

Col. Doctores 
La infiltración a la comisura anterior es de mal pronóstico. En la presente serie, la tasa de recaída en cT1b es ligeramente mayor (12.5\%) que en su contraparte cT1a, pero no se menciona si los primeros tenían este factor pronóstico adverso. Desafortunadamente, no se clasifican los tipos de cordectomía efectuados ni se evalúa si esta tiene un papel en la recurrencia ${ }^{5}$.

Los autores comparan la cirugía láser con la conservadora abierta, pero son procedimientos no comparables. Están diseñados para etapas diferentes: la cirugía transoral está indicada en cT1y selectos cT2, y la conservadora abierta en pacientes con tumores gloto-supraglóticos y glóticos con factores pronóstico adversos (comisura anterior, fijación cordal, etc.).

Con los excelentes resultados mostrados podemos concluir que la cirugía endoscópica láser es una alternativa, con el mismo valor que la radioterapia ha mostrado en estudios históricos en pacientes con carcinomas glóticos in situ o invasores limitados a la cuerda vocal, con movilidad normal, y que en pacientes cT2 es fundamental descartar factores pronóstico adversos que indiquen otro tipo de abordaje quirúrgico conservador o bien conservador no quirúrgico.

\section{Financiamiento}

El autor declara no haber recibido financiamiento para la elaboración de la presente.

\section{Conflicto de intereses}

El autor declara no tener conflictos de intereses.

\section{Responsabilidades éticas}

Protección de personas y animales. Los autores declaran que para esta investigación no se han realizado experimentos en seres humanos ni en animales.

Confidencialidad de los datos. Los autores declaran que han seguido los protocolos de su centro de trabajo sobre la publicación de datos de pacientes.

Derecho a la privacidad y consentimiento informado. Los autores declaran que en este artículo no aparecen datos de pacientes.

\section{Bibliografía}

1. Tamez-Velarde M, Moreno-Moreno OP, Sánchez-Larios R, González-Gutiérrez M, Girón-Archundia E. Microcirugía transoral con láser para el cáncer glótico temprano en un hospital de tercer nivel en Ciudad de México. Cir Cir 2020;88:325-330.

2. Warner L, Lee K, Homer JJ. Transoral laser microsurgery versus radiotherapy for T2 glottic squamous cell carcinoma: a systematic review of local control outcomes. Clin Otolaryngol. 2017;42:629-36.

3. Huang G, Luo M, Zhang J, Liu H. The voice quality after laser surgery versus radiotherapy of $\mathrm{T} 1 \mathrm{a}$ glottic carcinoma: systematic review and meta-analysis. Onco Targets Ther. 2017;10:2403-10.

4. Mo HL, Li J, Yang X. Transoral laser microsurgery versus radiotherapy for T1 glottic carcinoma: a systematic review and meta-analysis. Lasers Med Sci. 2017:32:461-7.

5. Remacle M, Van Haverbeke C, Eckel H, Bradley P, Chevalier D, Djuckic V, et al. Proposal for revision of de European Laryngological Society classification of endoscopic cordectomies. Eur Arch Otorhinolaryngol. 2007;264:499-504. 